\title{
PELATIHAN PEMBUATAN TERUMBU BUATAN BERBASIS ECO- FRIENDLY SEBAGAI SARANA REHABILITASI TERUMBU KARANG DI DAERAH PANTAI WISATA PASIR PUTIH, SITUBONDO
}

\author{
TRAINING OF ECO-FRIENDLY-BASED ARTIFICIAL REEFS AS A \\ MEANS OF CORAL REHABILITATION IN WHITE SAND BEACH \\ TOURISM, SITUBONDO
}

\author{
Agung Prasetyo Utomo ${ }^{1)}$, Mirna Apriani ${ }^{2)}$, Ruddianto ${ }^{3)}$, Luqman Cahyono ${ }^{4)}$, \\ Anggara Trisna Nugraha ${ }^{5}$, Mochammad Ilham Nugroho ${ }^{6}$ \\ ${ }^{1,3,6}$ Jurusan Teknik Bangunan Kapal, Politeknik Perkapalan Negeri Surabaya \\ ${ }^{2,4}$ Jurusan Teknik Permesinan Kapal, Politeknik Perkapalan Negeri Surabaya \\ ${ }^{5}$ Jurusan Teknik Kelistrikan Kapal, Politeknik Perkapalan Negeri Surabaya \\ ${ }^{1}$ Email: agungprasetyo@ppns.ac.id
}

\begin{abstract}
Abstrak: Indonesia merupakan negara kepulauan memiliki keanekaragaman hayati terbesar di dunia, hal ini disebabkan karena adanya keunikan topografi dasar laut Indonesia. Salah satu keanekaragaman spesies yang ada adalah 950 biota terumbu karang sebagai habitat dan ekosistem laut. Terumbu karang berfungsi sebagai tempat memijah biota laut, pelindung gempuran ombak bagi pantai dan bernilai estetika. Pantai wisata Pasir Putih Situbondo termasuk andalan tempat wisata di Jawa Timur. Pantai ini memiliki terumbu karang yang berada pada nilai $23-49 \%$ yang termasuk ke dalam kategori rendah. Pantai di Situbondo ini memiliki dua site dalam kondisi baik dan dua site dalam kondisi cukup. Agar kondisi terumbu karang meningkat menjadi kategori sangat baik dan mencegah adanya kerusakan, diperlukan upaya untuk melakukan rehabilitasi. Salah satu upaya dapat dilakukan menggunakan terumbu karang buatan dari cangkang kerang dan beton yang dihasilkan dari masyarakat sekitar pantai. Pemberdayaan masyarakat perlu dilakukan untuk mendukung pelestarian terumbu karang yang dapat mempengaruhi keberadaan ikan dan biota laut lainnya. Pemberdayaan masyarakat ini difokuskan pada aktivis lingkungan, kelompok masyarakat pengawas (pokmaswas), serta masyarakat di daerah lingkungan wisata Pasir Putih diawali dengan pembekalan pengalaman dan ketrampilan dalam pembuatan terumbu karang berbasis eco-friendly. Kegiatan meliputi penyampaian materi secara hybrid (luring dan daring), praktik pembuatan terumbu buatan, penenggelaman hasil terumbu buatan dan monitoring.
\end{abstract}

Kata Kunci: Terumbu buatan, Eco friedly, Cangkang kerang, Pasir putih

Abstract: Indonesia is an archipelagic country that has the largest biodiversity in the world, this is due to the unique topography of the Indonesian seabed. One of the existing species diversity is 950 coral reef biota as habitat and marine ecosystem. Coral reefs serve as spawning grounds for marine life, protection against waves for the beach, and aesthetic value. The white sand beach of 
Situbondo is a mainstay of tourist attractions in East Java. This beach has coral reefs that are at a value of 23-49\% which is included in the low category. This beach in Situbondo has two sites in good condition and two sites in moderate condition. To improve the condition of coral reefs into a very good category and prevent damage, efforts are needed to carry out rehabilitation. One effort can be made using artificial coral reefs from shells and concrete produced from communities around the coast. Community empowerment needs to be done to support the preservation of coral reefs which can affect the presence of fish and another marine biota. Community empowerment is focused on environmental activists, community supervisory groups (pokmaswas), and communities in the Pasir Putih tourist area, beginning with the provision of experience and skills in making eco-friendly coral reefs. Activities include hybrid delivery of materials (offline and online), the practice of making artificial reefs, sinking of artificial reefs, and monitoring.

Keywords: Artificial reef, Eco friendly, Shells, White sand

\section{PENDAHULUAN}

Indonesia sebagai negara maritim memiliki garis terpanjang kedua di dunia, berpotensi meningkatkan produktivitas dan keberlanjutan ekosistem laut (KKP, 2017). Indonesia adalah negara kepulauan dengan luas wilayah perairan sebesar $3.257 .483 \mathrm{~km}^{2}$, 13.466 pulau dan dengan panjang garis pantai $99.093 \mathrm{~km}$. Ekosistem terumbu karang berada di sekeliling pulau dan sepanjang garis pantai, mempunyai banyak peranan namun rentan terhadap perubahan lingkungan. Ekosistem terumbu karang sebagai habitat, berfungsi menjadi tempat memijah biota laut, melindungi pantai dari gempuran ombak dan memiliki nilai estetika. Selain berfungsi dari segi ekologi, terumbu karang juga berperan dalam segi sosial ekonomi melalui potensi hasil perikanan dan wisata bahari bagi masyarakat pesisir. Mengingat begitu penting manfaatnya, diharapkan terumbu karang ini mendapatkan perhatian selain dari pemerintah juga oleh masyarakat, pengusaha dan semua pihak (Hadi dkk., 2018).

Kerusakan terumbu karang dapat disebabkan akibat kegiatan wisata, pembangunan di daerah pesisir, pencemaran dan penangkapan ikan yang tidak sesuai aturan (Saputra dkk., 2016). Pantai Wisata Pasir Putih Sitobondo adalah salah satu andalan tempat wisata di Jawa Timur. Pantai ini berjarak kurang lebih $23 \mathrm{~km}$ di sebelah barat Situbondo, terkenal dengan pantainya yang landai dan berPasir Putih (Muthahharah dan Adiwibowo, 2015). Kondisi terumbu karang di 
INTEGRITAS : Jurnal Pengabdian

Vol 5 No 2 Desember 2021

ISSN $2580-7978$ (cetak) ISSN 2615 - 0794 (online)

Pasir Putih Sitobondo berada pada nilai 23-49\% yang termasuk ke dalam kategori rendah. Hal ini dapat mengancam keberadaan ikan yang sangat bergantung pada terumbu karang (Luthfi dan Yamindago, 2008). Pasir Putih memiliki 4 (empat) site terumbu karang berada dalam kondisi baik dan cukup dengan masing-masing berjumlah 2 (dua) site (Hadi dkk., 2018).

Selain permasalahan di atas, terdapat pula permasalahan lainnya, yaitu limbah cangkang kerang yang dapat mengganggu lingkungan pesisir pantai Pasir Putih. Limbah cangkang kerang ini membuat penumpukan sampah dan sulit untuk terurai. Sebagaian masyarakat hanya memanfaatkan limbah cangkang kerang sebagai bahan kerajinan saja. Sehingga perlu solusi pemanfatan limbah cangkang kerang yang masih belum maksimal.

Berdasarkan permasalahan di atas, penulis memanfaatkan limbah cangkang kerang sebagai upaya pencegahan dan penanggulangan kerusakan terumbu karang. Hal tersebut diperlukan agar kondisi terumbu tetap terjaga dengan baik dan cukup, tidak menurun menjadi kondisi buruk. Hal ini dapat dilakukan melalui pemberdayaan masyarakat di pantai Pasir Putih untuk melakukan rehabilitasi terumbu karang menggunakan terumbu buatan. Terumbu buatan dapat dihasilkan melalui campuran bahan baku dari beton dan cangkang kerang. Pemanfaatan cangkang kerang merupakan salah satu upaya mengolah limbah padat berupa cangkang kerang dari proses pemasakan kerang menjadi makanan. Pengolahan limbah cangkang kerang sebagai bahan baku terumbu buatan termasuk ke dalam upaya pengelolaan melalui reuse, recycle dan recovery. Pemberdayaan masyarakat harus diawali dengan pembekalan pengalaman dan ketrampilan dalam pembuatan terumbu berbasis eco-friendly pada para aktivis lingkungan, kelompok masyarakat pengawas (pokmaswas), serta masyarakat di daerah lingkungan wisata Pasir Putih. Sehingga diperlukan pelatihan pembuatan terumbu buatan melalui kegiatan pengabdian kepada masyarakat untuk pembelajaran dan sharing knowledge.

\section{METODE}

Kegiatan pengabdian kepada masyarakat berupa pelatihan pembuatan terumbu buatan dilaksanakan melalui tahap persiapan dan pelaksanaan dimana 
pemilihan metode yang dilakukan dalam kegiatan adalah dengan metode pelatihan berupa ceramah, diskusi dan praktik baik melalui video tutorial maupun praktik langsung melalui pembuatan terumbu buatan kepada para aktivis lingkungan, kelompok masyarakat pengawas (pokmaswas), serta masyarakat di daerah lingkungan wisata Pasir Putih, Situbondo dan dilanjutkan Penenggelaman hasil terumbu buatan. Untuk detail kegiatan pengabdian dapat dilihat pada diagram alir (gambar 1).

\section{Tahap Persiapan}

Tahap persiapan terdiri dari persiapan peralatan, bahan, percobaan pembuatan terumbu buatan, pembuatan tutorial berupa media tulisan dan video. Percobaan pembuatan terumbu dilakukan agar dapat memberikan contoh nyata terumbu karang yang akan dipraktikkan dalam pelatihan. Persiapan dilakukan meliputi kegiatan pengumpulan cangkang kerang, pembelian semen, pasir sebagai bahan campurannya dan pembuatan cetakan.

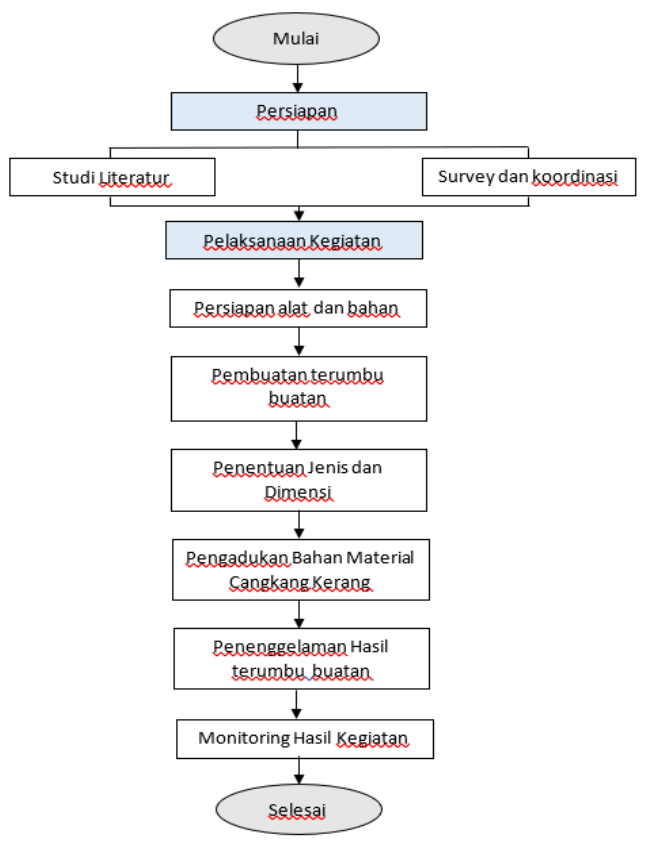

Gambar 1. Diagram Alir Kegiatan

Cetakan untuk membuat terumbu berbentuk piramida berdimensi $60 \mathrm{~cm} \mathrm{x}$ $60 \mathrm{~cm}$ x $30 \mathrm{~cm}$, diilustrasikan pada Gambar 2. Menurut Saptarini,dkk. (2010) ditinjau dari persentase komposisi jenis larva planktonic terumbu buatan berbetuk kubus berongga tersusun pyramid memiliki nilai persentase $61,9 \%$ lebih besar 
dibanding bentuk lainnya. Selanjutnya untuk dimensi diameter rongga terumbu buatan sebesar $7 \mathrm{~cm}$ dan tebal dinding berukuran 7-10 $\mathrm{cm}$. Bahan baku untuk terumbu buatan jenis piramida adalah $315,4 \mathrm{~kg}$ semen, $1.503,7 \mathrm{~kg}$ pasir, 375,9 $\mathrm{kg}$ cangkang kerang, dan 205 liter air. Campuran tersebut merupakan pengukuran berat dalam volume beton per $1 \mathrm{~m}^{3}$ (Akhwady dan Bayuaji, 2017).

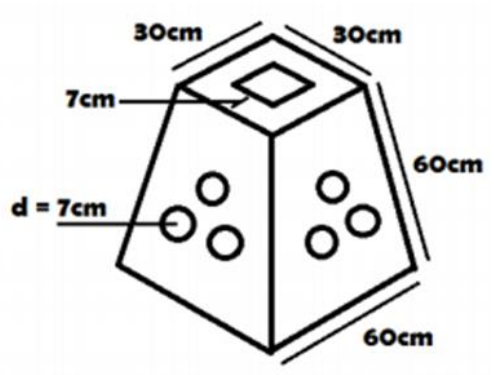

Gambar 2. Cetakan Terumbu Buatan

\section{Tahap Pelaksanaan}

Tahap pelaksanaan kegiatan pelatihan dilakukan secara hybrid (secara luring dan daring) karena masih dalam kondisi pandemi Covid-19. Kegiatan dengan metode hybrid ini salah satu solusi kegiatan pengabdian kepada masyarakat dalam kondisi yang serba terbatas yakni kondisi pandemi Covid-19 (ruddianto, dkk, 2021). Pelaksanaan kegiatan dilaksanakan di daerah pantai wisata Pasir Putih kabupaten Situbondo.

\section{HASIL DAN PEMBAHASAN}

\section{Survey dan Koordinasi Awal}

Survey dan koordinasi awal dilakukan sebelum proses kegiatan pelatihan dilakukan yakni dengan menemui pihak yang terkait diantara pada bagian Konservasi Karang Lestari Pasir Putih Situbondo. Pada kegiatan ini beberapa hal yang dibahas yakni terkait waktu dan tempat pelaksanaan kegiatan, jumlah peserta pelatihan, sarana dan prasarana baik saat proses pemaparan materi dan video, proses praktik pembuatan hingga proses penenggelaman terumbu buatan. Pada tahap ini diperoleh hasil koordinasi yakni : 
a. Pelaksanaan akan dilaksanakan 2 hari (1-2 September 2021),

b. Jumlah peserta kegiatan 15 orang peserta yang terdiri dari para aktivis lingkungan, kelompok masyarakat pengawas (pokmaswas), serta masyarakat di daerah lingkungan wisata Pasir Putih,

c. Jumlah panitia yang terlibat pada kegiatan sebanyak 5 orang

Dimana jumlah peserta dan panitia yang terlibat melihat pada kegiatan menyesuaikan dari luas ruangan yang diharuskan menerapkan standart protokol kesehatan Covid-19.

\section{Pelaksanaan Kegiatan}

Pelaksanaan kegiatan Pelatihan Pembuatan Terumbu Buatan Berbasis Eco Friendly Berbahan Material Beton dan Cangkang Kerang Sebagai Sarana Rehabilitasi Terumbu Karang di Daerah Pantai Wisata Pasir Putih, Situbondo dilaksanakan selama 2 hari (1-2 September 2021). Pada tanggal 1 September 2021 dilakukan kegiatan diseminasi yakni dengan paparan materi dan video tutorial/pembuatan Terumbu Buatan Berbasis Eco Friendly dilanjutkan dengan melakukan pembuatan terumbu buatan bersama peserta kegiatan dengan bahan dan alat yang telah dipersiapkan sebelumnya. Pada awal kegiatan, proses pembukaan acara dibuka secara virtual (metode hybrid) oleh Ketua Jurusan Teknik Bangunan Kapal (KAJUR TBK) Politeknik Perkapalan Negeri Surabaya (PPNS) oleh Bapak Ruddianto,ST,MT,MRINA dan dilanjutkan sambutan dari Ketua Konservasi Karang Lestari Pasir Putih Situbondo.

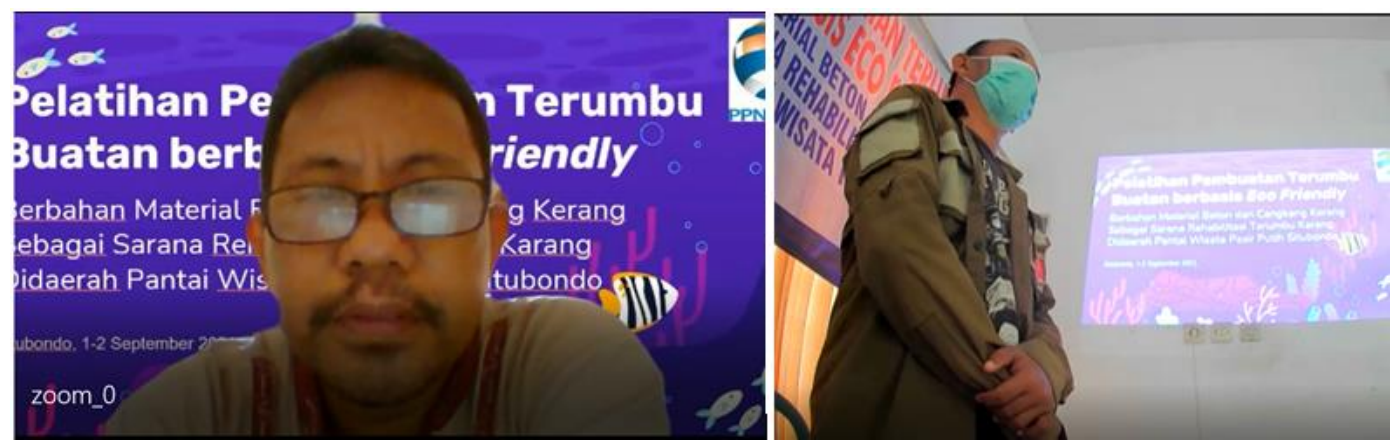

Gambar 3. Pembukaan acara oleh Kajur TBK dan Ketua Konservasi Karang Lestari Pasir Putih Situbondo

Setelah proses pembukaan kegiatan, acara dilanjutkan proses pamaparan materi tentang tentang Terumbu Buatan Berbasis Eco Friendly Berbahan Material 
Beton dan Cangkang Kerang Sebagai Sarana Rehabilitasi Terumbu Karang. Kegiatan ini dilakukan dengan menggunakan metode ceramah kemudian disambung dengan proses tanya jawab baik dari peserta secara luring dan daring. Para peserta kegiatan sangat antusias dalam proses pemaparan materi, hal ini bisa dilihat dari peserta yang focus menyimak materi, banyaknya peserta yang bertanya, memberikan tanggapan hingga masukan terkait kondisi lingkungan perairan pantai, kondisi terumbu karang hingga limbah yang terjadi dilingkungan sekitar pesisir. Pemateri memberikan beberapa berita terkini tentang kondisi pantai Pasir Putih, proses penyebab terjadinya kerusakan lingkungan serta beberapa pemanfaatan limbah yang berada didaerah sekitar pesisir menjadi topik yang sangat menarik yang sangat erat dalam kehidupan sehari-hari.

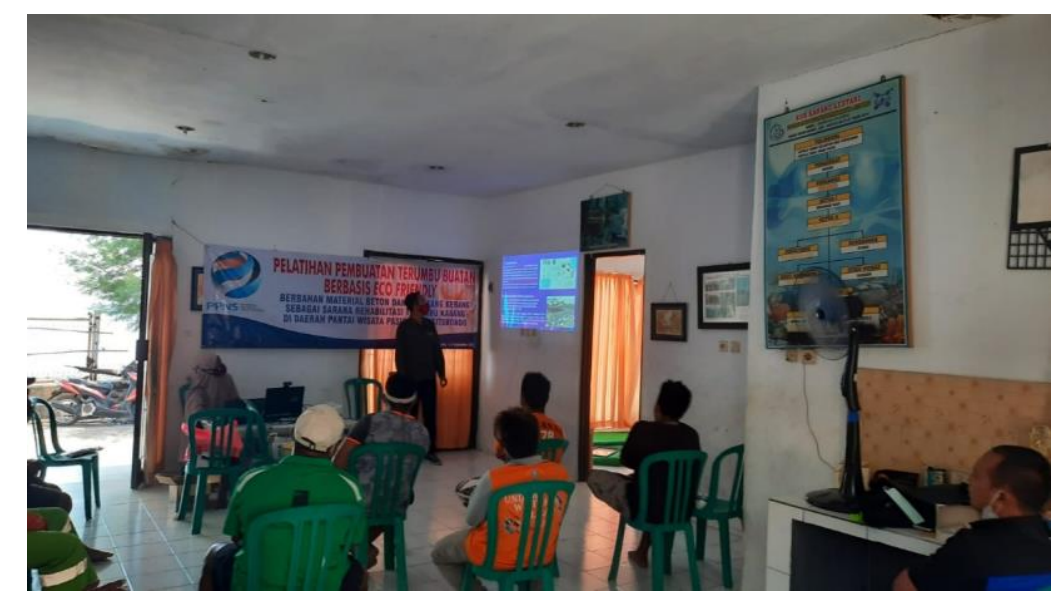

Gambar 4. Paparan materi kegiatan secara hybrid

Video tutorial/pembuatan Terumbu Buatan Berbasis Eco Friendly ditampilkan dengan tujuan memberikan gambaran pada peserta kegiatan proses pembuatan terumbu karang buatan, pelaksanaan pembuatan dimulai dari :

1. Desain awal

Proses desain awal digunakan untuk menetukan dimensi/ukuran dari terumbu buatan yang akan dibuat. Desain awal ini diperoleh berdasarkan beberapa penelitian sebelumnya. Menurut saptarini, et al. (2010) ditinjau dari persentase komposisi jenis larva planktonic didesain terumbu buatan bentuk reefball memiliki nilai sebesar $60 \%$, desain terumbu buatan berbetuk kubus berongga tersusun pyramid memiliki nilai $61,9 \%$ dan terumbu buatan bentuk 
kubus berongga tersusun tersebar memiliki nilai 57,9\%. Sehingga gambaran desain terumbu buatan berbentuk piramida yang akan digunakan pada pengabdian masyarakat ini.
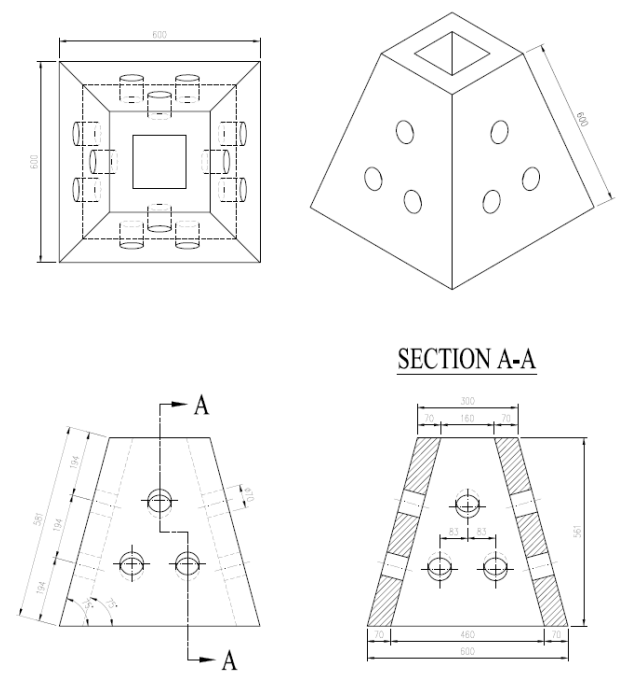

Gambar 5. Desain ulang dimensi terumbu buatan bentuk piramida

2. Persiapan alat dan bahan

Beberapa alat dan bahan yang digunakan pada kegiatan pembuatan terumbu buatan ini diantaranya:

Bahan : Pasir, Semen, Cangkang Kerang, Lem, Besi Cor, Kawat, Triplek, Pelumas

Alat : Gerinda Potong, Bor, mur dan baut, Skrup, Timbangan, Pengaduk, Palu, Obeng

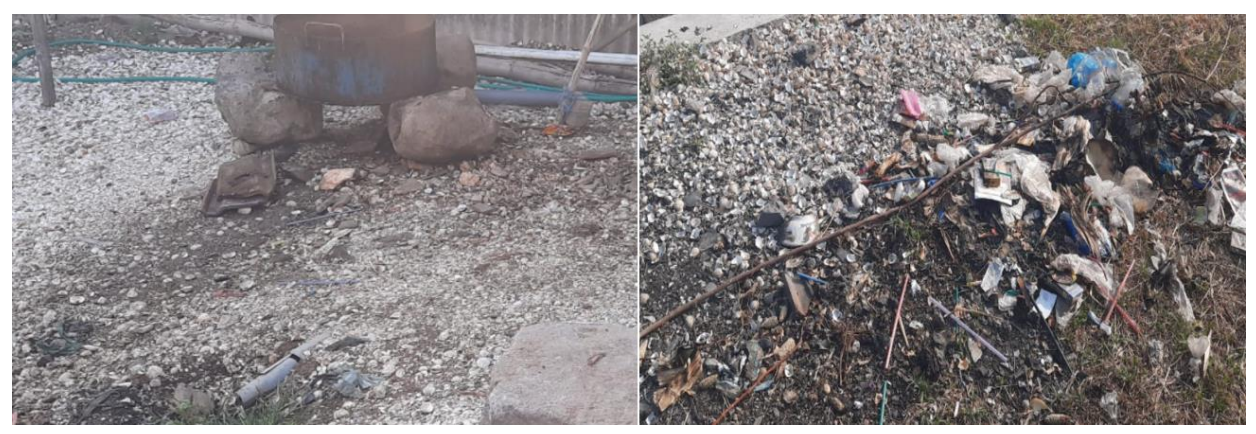

Gambar 6. Bahan cangkang kerang disekitar pesisir pantai

Pada Gambar 6 diatas merupakan salah satu contoh limbah cangkah kerang, dimana pemanfaatan cangkang kerang hanya dibuang dan hanya sebagian kecil dimanfaatkan sebagai kerajinan, maka dari itu pemanfaatan 
cangkang kerang bisa dipakai sebagai campuran beton pada terumbu buatan. Cangkang kerang memiliki kandungan $\mathrm{CaCO}_{3}$, kandungan $\mathrm{CaCO}_{3}$ sendiri merupakan zat penyusun utama terumbu. Pemanfaatan cangkang kerang sebagai campuran beton untuk terumbu buatan diharapkan membantu proses rehabilitasi terumbu karang.

3. Marking/penandaan cetakan

Proses penandaan cetakan dalam hal ini menggunakan triplek sebagai bahan cetakan, proses ini dilakukan setelah dimensi terumbu buatan yang dibuat sebelumnya telah benar.

4. Pemotongan cetakan

Setelah proses penandaan maka dilakukan proses pemotongan cetakan terumbu buatan dengan menggunakan bantuan alat potong. Pemotongan cetakan harus sesuai dengan pola penandaan pada proses marking sebelumnya, sehingga hasil yang diperoleh akan sesuai dengan desain yang telah dibuat.

5. Assembly cetakan

Proses Assembly cetakan dilakukan setelah pemotongan cetakan telah selesai, proses ini merupakan penggambungan dari beberapa potongan yang telah diproses sebelumnya. Assembly akan menghasilkan bentuk cetakan yang akan digunakan dalam proses pembauatan cangkang buatan.

6. Penentuan komposisi bahan

Pada proses penentuan komposisi bahan yakni Semen, pasir dan cangkang kerang haruslah sesuai dengan standart atau beberapa penelitian sebelumnya.

7. Proses mixing bahan, Pengecoran, Pengeringan dan Finishing

Proses selanjutnya proses pencampuran/mixing bahan sesuai komposisi yang ditentukan, dimana proses pencampuran agregat pasir, semen dan limbah cangkang kerang harus merata. Proses pengecoran ini harus dilakukan secepat mungkin agar proses pengeringan dari terumbu buatan bersamaan. 


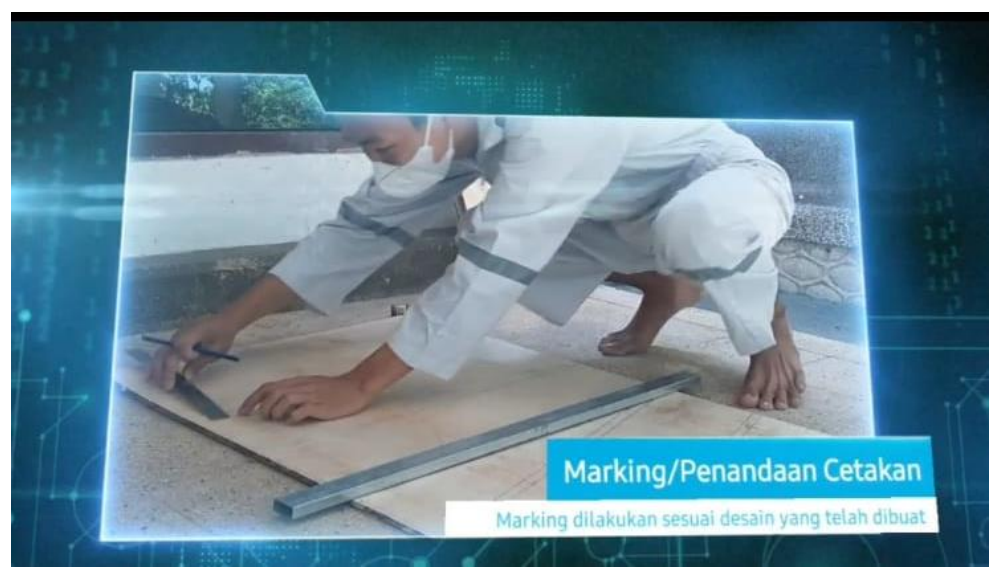

Gambar 7. Video tutorial/pembuatan Terumbu Buatan Berbasis Eco Friendly

Setelah pemaparan materi dan pemutaran video tutorial pembuatan terumbu karang buatan, langkah selanjutnya adalah praktik bersama para peserta kegiatan. Proses ini dimulai dari penentuan komposisi bahan, dengan bahan yang telah disiapkan sebelumnya serta peralatan penunjang kegiatan. Proses kegiatan melalui praktik dimulai penentuan komposisi bahan hingga Proses mixing bahan, Pengecoran, Pengeringan dan Finishing. Kegiatan ini dilakukan diluar ruangan mengingat kondisi ruang yang cukup sempit serta bisa dilanjutkan dengan proses pengeringan terumbu buatan.

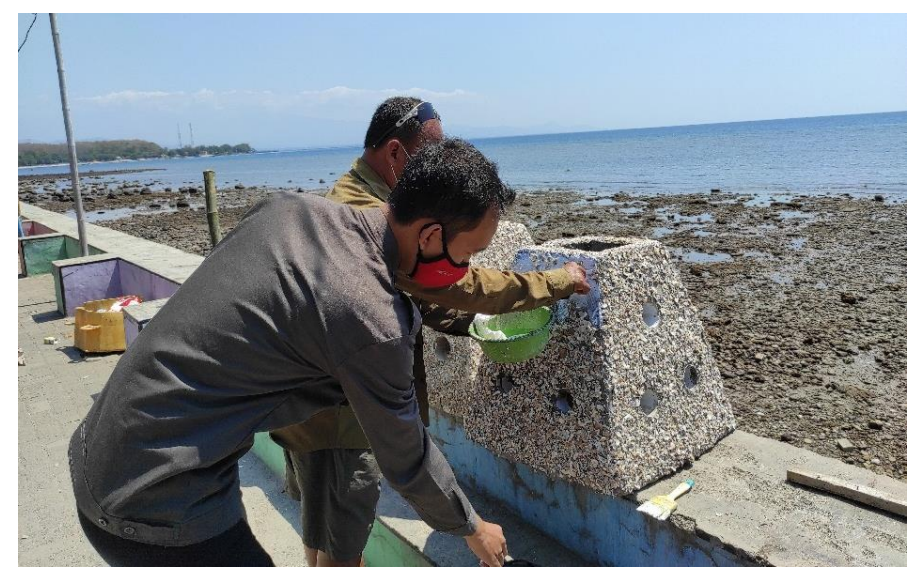

Gambar 8. Proses penentuan komposisi bahan dan penambahan pengecoran

Pelaksanaan kegiatan pada hari kedua (2 September 2021) adalah proses penenggelaman terumbu buatan dilokasi/pusat konservasi terumbu karang dengan koordinat S $07^{\circ} 41^{\prime} 19,9^{\prime \prime}$ E $113^{\circ} 49^{\prime} 40,95$. Kegiatan penenggelaman terumbu karang ini selain dengan para peserta kegiatan (aktivis lingkungan, kelompok masyarakat pengawas (pokmaswas), serta masyarakat di daerah lingkungan wisata 
Pasir Putih) dibantu oleh tim diving dan penyelam dari Konservasi Karang Lestari Pasir Putih Situbondo. Kegiatan ini dimulai dari proses pengangkuatan terumbu buatan ke dalam perahu, proses pemindahan/pengangkatan sesuai koordinat hingga penyusunan terumbu buatan pada area konservasi terumbu karang pantai Pasir Putih, Situbondo.

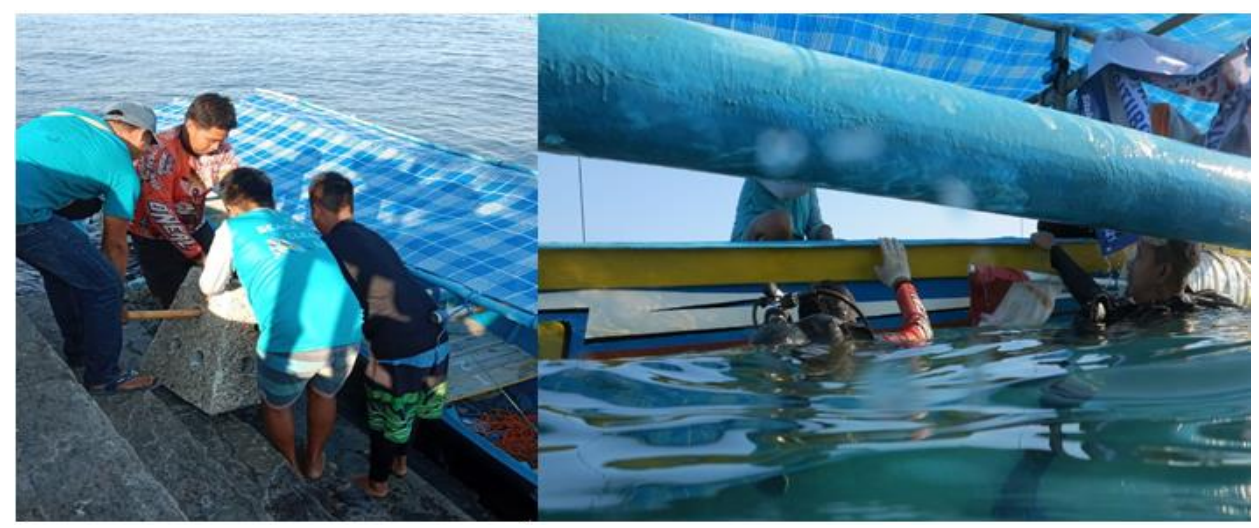

Gambar 9. Proses pengangkutan terumbu buatan

Waktu pelaksanaan kegiatan dihari kedua ini lebih pagi dari pada hari pertama, dimana pada pagi hari sekitar pukul 07.00 wib kondisi perairan dalam keadaan air laut pasang, sehingga memudahkan untuk memindah terumbu buatan dan perahu bisa bersandar pada tepi dermaga menuju koordinat yang ditentukan.

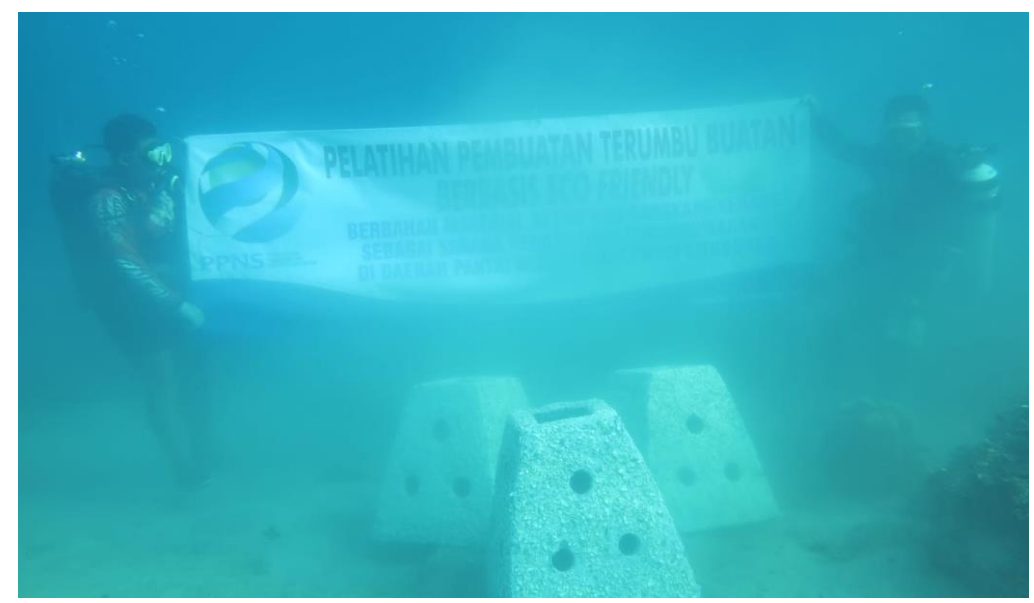

Gambar 10. Proses penenggelaman terumbu buatan

Setelah proses penenggelaman terumbu buatan, langkah selanjutnya adalah monitoring hasil serta evaluasi bersama Konservasi Karang Lestari Pasir Putih Situbondo. 


\section{KESIMPULAN}

Berdasarkan hasil kegiatan pengabdian kepada masyarakat yang telah dilakukan, dapat ditarik kesimpulan secara umum dan khusus yaitu :

1. Secara umum kegiatan ini dapat memberikan tambahan informasi kepada pihak pemerintah, aktivis lingkungan dan masyarakat didaerah pantai wisata Pasir Putih Situbondo khususnya tetang lingkungan bawah peariran yakni daerah terumbu karang untuk lebih menjaga dan melestarikan hingga merawatnya.

2. Secara khusus, kegiatan ini menitikberatkan pada pelatihan skill masyarakat mengolah limbah cangkang kerang sebagai bahan campuran Pembuatan Terumbu Buatan Berbasis Eco Friendly Berbahan Material Beton dan Cangkang Kerang Sebagai Sarana Rehabilitasi Terumbu Karang di Daerah Pantai Wisata Pasir Putih, Situbondo, sehingga dengan adanya pelatihan dan penelitian sebelumnya Terumbu Buatan Berbasis Eco Friendly Berbahan Material Beton dan Cangkang dapat direkomendasikan sebagai Sarana Rehabilitasi Terumbu Karang.

3. Peserta pelatihan yang terlibat dalam kegiatan sesuai jumlah yang ditargetkan didaerah panatai Pasir Putih Situbondo dimana pada saat koordinasi awal jumlah peserta yang hadir sesuai dengan jumlah diundang (luring), peserta yang mengikuti pelatihan juga beragam dari aktivis lingkungan, kelompok masyarakat pengawas (pokmaswas), serta masyarakat di daerah lingkungan wisata Pasir Putih. Dengan demikian dapat dikatakan bahwa target peserta tercapai $100 \%$. Angka tersebut menunjukkan bahwa kegiatan ini dilihat dari jumlah peserta yang mengikuti dapat dikatakan berhasil/ sukses. Serta masyarakat yang dituju pada kegiatan pengabdian ini telah sesuai dengan yang diinginkan.

4. Ketercapaian tujuan dari pengabdian masyarakat ini telah tercapai, hal itu dapat ditunjukkan dengan keberhasilan peserta dalam praktik pembuatan terumbu buatan secara langsung dari awal hingga akhir proses dengan hasil yang memuaskan. Hal itu menunjukkan pula bahwa kompetensi dan keterampilan peserta dalam pembuatan terumbu buatan ini sudah berhasil 
diimplementasikan dengan baik. Waktu pelaksanaan telah sesuai, sehingga semua materi dapat tersampaikan dengan baik.

\section{UCAPAN TERIMA KASIH}

1. Ketua Konservasi Karang Lestari Pasir Putih Situbondo berserta Tim, yang memberikan masukan dalam kegiatan serta sarana dan prasarana hingga para peserta kegiatan, sehingga kegiatan ini dapat berjalan dengan baik dan lancar.

2. Politeknik Perkapalan Negeri Surabaya atas kepercayaan dan motivasi untuk melaksanakan kegiatan pengabdian kepada masyarakat.

3. Tim dosen dan mahasiswa yang telah menyelesaikan kegiatan pengabdian kepada masyarakat dari awal hingga akhir kegiatan.

4. Kawan aktivis lingkungan, kelompok masyarakat pengawas (pokmaswas), serta masyarakat di daerah lingkungan wisata Pasir Putih yang meluangkan waktu dan kesempatan untuk dalam menykseskan desiminasi kegiatan terumbu buatan berbasis eco friendly berbahan material beton dan cangkang sebagai sarana rehabilitasi terumbu karang didaerah pantai wisata Pasir Putih, Situbondo.

\section{DAFTAR PUSTAKA}

Akhwady, R., \& Bayuaji, R. 2017. The Influence of Clamshell on Mechanical Properties of NonStructure Concrete as Artificial Reef. Asian Journal of Applied Sciences, Volume 05(02).

Hadi, T, A., Giyanto, Prayudha, B., Hafitz, M., Budiyanto, A., Suharsono. 2018. Status Terumbu Karang Indonesia. Jakarta : Puslit Oseanografi - LIPI.

Kementrian Kelautan dan Perikanan (KKP). 2017. KKP news about World Ocean Summit Panel "What Comes Next: A Call for Commitments on February, 24 2017.available from: http://news.kkp.go.id.

Luthfi, O. M., \& Yamindago, A. 2008. Telaah Struktur Komunitas Terumbu Karang Sebagai Studi Awal Program Rehabilitasi Terumbu Karang Di Perairan Pasir Putih Situbondo. Fakultas Perikanan Dan Ilmu Kelautan, Universitas Brawijaya, Malang.

Muthahharah, A., \& Adiwibowo, S. 2017. Dampak Obyek Wisata Pantai Pasir Putih Situbondo terhadap Peluang Bekerja dan Berusaha. Jurnal Sains Komunikasi dan Pengembangan Masyarakat, Volume (2): 157-166.

Ruddianto., Utomo, P.A., Sumardiono., Abdullah, K., Wulandari, K.D., Workshop Online Pembuatan Kapal Kecil Untuk Nelayan Dikabupaten Situbondo 
INTEGRITAS : Jurnal Pengabdian

Vol 5 No 2 Desember 2021

ISSN 2580 - 7978 (cetak) ISSN 2615 - 0794 (online)

Saptarini, D., Aunurohim, \& Fahlusi, N.I. 2010. Komposisi dan kelimpahan Larva invertebrate Planktonok pada Tiga Desain Terumbu Buatan di Pantai Pasir Putih, Bungatan, Situbondo, Jawa Timur. Jurusan Biologi, Institut Teknologi Sepeuluh Nopember Surabaya

Saputra, S. A., Ignasius Pramana Yuda, \& Felicia Zahida. 2016. Keanekaragaman dan Penutupan Terumbu Karang di Pantai Pasir Putih Situbondo, Jawa Timur. Fakultas Teknobiologi Universitas Atma Jaya Yogyakarta. 